\title{
Enzymatic Synthesis of Sorboyl-Polydatin Prodrug in Biomass-Derived 2-Methyltetrahydrofuran and Antiradical Activity of the Unsaturated Acylated Derivatives
}

\author{
Zhaoyu Wang,, Yanhong Bi, ${ }^{1}$ Rongling Yang, ${ }^{1}$ Xiangjie Zhao, ${ }^{1}$ Ling Jiang, ${ }^{2}$ Chun Zhu, \\ Yuping Zhao, ${ }^{1}$ and Jianbo Jia ${ }^{1}$ \\ ${ }^{1}$ School of Life Science and Food Engineering, Huaiyin Institute of Technology, Huai'an 223003, China \\ ${ }^{2}$ College of Food Science and Light Industry, Nanjing Tech University, Nanjing 211816, China
}

Correspondence should be addressed to Zhaoyu Wang; biowzy@126.com and Yanhong Bi; byhfood@126.com

Received 31 May 2016; Revised 3 August 2016; Accepted 7 August 2016

Academic Editor: Pengjun Shi

Copyright (C) 2016 Zhaoyu Wang et al. This is an open access article distributed under the Creative Commons Attribution License, which permits unrestricted use, distribution, and reproduction in any medium, provided the original work is properly cited.

\begin{abstract}
Efficient and highly regioselective synthesis of the potential $6^{\prime \prime}$-O-sorboyl-polydatin prodrug in biomass-derived 2-methyltetrahydrofuran (2-MeTHF) was achieved using Candida antarctica lipase B for the first time. Under the optimal conditions, the initial reaction rate, maximum substrate conversion, and $6^{\prime \prime}$-regioselectivity were as high as $8.65 \mathrm{mM} / \mathrm{h}, 100 \%$, and $100 \%$, respectively. Kinetic and operational stability investigations evidently demonstrated excellent enzyme compatibility of the 2-MeTHF compared to the traditional organic solvents. With respect to the antioxidant properties, three unsaturated ester derivatives showed slightly lower DPPH radical scavenging activities than the parent agent. Interestingly, further studies also revealed that the antiradical capacities of the acylates decreased with the elongation of the unsaturated aliphatic chain length from $\mathrm{C} 4$ to $\mathrm{C} 11$. The reason might be attributed to the increased steric hindrance derived from the acyl residues in derivatives.
\end{abstract}

\section{Introduction}

Polydatin (also known as piceid and resveratrol-3-O- $\beta$ mono-D-glucoside) is the key pharmacodynamic constituent from Polygonum cuspidatum Sieb. et Zucc. which is an extensively used traditional Chinese medicinal plant in the clinical treatment of platelet aggregation, diabetes mellitus, ischemia-reperfusion injuries, and burn-generated cardiac dysfunction, and so forth $[1,2]$. Nowadays, the highly lipophilic drugs are becoming more and more prevalent and well designed with enhanced pharmacological activity in pharmaceutical industry $[3,4]$. However, similar to other original natural drugs, polydatin generally suffers from poor solubility, low bioavailability, and unsatisfactory stability in lipid formulations because of its polyhydroxy structure [5]. Consequently, in order to overcome the aforementioned disadvantages and improve the bioavailability in lipid systems, one of the most effective strategies is to synthesize ester prodrugs of polydatin. For example, structure-function relationships revealed that the acylated derivatives of rutin, pruning, and naringin presented improved biological activities and physicochemical properties compared to the corresponding parental agents $[6,7]$. Moreover, further investigations also found that natural compounds modified by $\alpha$ - or $\beta$ unsaturated groups usually displayed the higher biological activity compared with the parent agents $[8,9]$.

Chemically, the acyl chlorides and anhydrides are usually required as acylating reagents for acylating flavonoids, which are characterized by the poor selectivity, tedious protectionunprotection steps, and low product yields [10]. Fortunately, enzymatic strategy instead of conventional chemical method has been well established for acylating compounds possessing similar reactive hydroxyl groups [11]. Recently, our research group has successfully explored an efficient and practical enzymatic route for the regioselective acylation of polyhydroxy nucleosides by using medium engineering, enzyme engineering, and substrate engineering strategies with excellent regioselectivities and conversions [12, 13]. 
<smiles>CC(CO)C(O)C(O)C(O)Oc1cc(O)cc(C=Cc2ccc(O)cc2)c1</smiles>

Polydatin

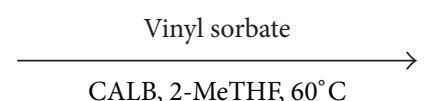

CALB, 2 -MeTHF, $60^{\circ} \mathrm{C}$

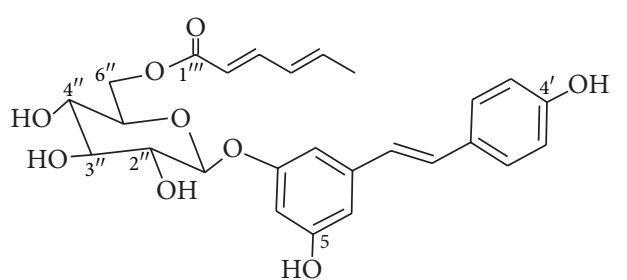

$6^{\prime \prime}$-O-Sorboyl-polydatin

SCHEme 1: CALB-catalyzed acylation of polydatin with vinyl sorbate.

Over the past several years, biobased solvents, that is, green solvents derived from renewable raw materials, have aroused great interest as environmentally friendly alternatives to traditional organic solvents in catalysis and organic chemistry, particularly in biocatalytic reactions with promising physicochemical properties of renewability, biodegradability, environmental benignancy, stability, and so forth [14]. Among these specific solvents, 2-MeTHF produced from renewable resources of lignocellulosic biomass, such as corn crops, bagasse, and oat hulls, exerts clear advantages like the low miscibility with water, high boiling point $\left(82^{\circ} \mathrm{C}\right)$, negligible toxicity, higher stability, and abiotic degradability by exposure to sunlight and air $[14,15]$. Following the pioneering work of Simeó and coworkers in enzymatic acylation of nucleosides in 2-MeTHF [16], biocatalysts have shown higher activity and stability in this ecofriendly medium than in traditional organic solvents.

Therefore, in this study, an effective enzymatic method in 2-MeTHF is explored for preparing potential dual prodrug of sorbic acid (an unsaturated fatty acid with noticeable bactericidal and fungicidal properties) ester of polydatin catalyzed by Candida antarctica lipase B (CALB), a versatile enzyme immobilized on macroporous acrylic resin with a molecular weight of $33 \mathrm{kDa}$ and approximate dimensions of $10 \AA \times 4 \AA \times 12 \AA[17,18]$ (Scheme 1). The kinetic study of the acylation was explored in detail to better identify the effect of 2-MeTHF on the performance of the enzyme. Particularly, the free radical scavenging activities of several unsaturated acylated derivatives were also preliminarily studied.

\section{Materials and Methods}

2.1. Materials. CALB (Candida antarctica lipase B immobilized on macroporous acrylic resin, $10000 \mathrm{U} / \mathrm{g}$ ) was from Novozymes Co., Ltd., China. Vinyl sorbate, vinyl undecenoate, and vinyl crotonate were obtained from TCI. Polydatin, 2,2-diphenyl-1-picrylhydrazyl (DPPH), 2-MeTHF, and $t$-amyl alcohol were purchased from Sigma-Aldrich. All other reagents were of analytical grade and were dried by $4 \AA$ molecular sieves.

2.2. Enzymatic Acylation Procedure. The acylation was conducted with polydatin $(0.03 \mathrm{mmol})$, vinyl sorbate $(0.27 \mathrm{mmol})$, anhydrous solvent $(3 \mathrm{~mL})$, and $100 \mathrm{mg}$ lipase while stirring at $200 \mathrm{rpm}$ and at a certain temperature. To determine the concentrations of the polydatin and regioselectivities of the acylated products, aliquot fractions $(50 \mu \mathrm{L})$ were withdrawn at specified time intervals from the reaction system, followed by a HPLC analysis. All experiments were conducted at least in triplicate and the errors did not exceed $5 \%$. No chemical acylation was detectable as confirmed by the control experiments.

2.3. Operational Stability of CALB. After the maximum substrate conversion reached during the batch acylation of polydatin, the immobilized enzyme was separated by filtration and washed three times with 2-MeTHF or THF. Then, the reused prepared catalyst was added into the fresh reaction mixture $(3 \mathrm{~mL})$ containing $0.03 \mathrm{mmol}$ polydatin, $0.45 \mathrm{mmol}$ vinyl crotonate, and $100 \mathrm{mg}$ CALB at $60^{\circ} \mathrm{C}$ and $200 \mathrm{rpm}$, followed by the assay of its activity and maximum polydatin conversion. The initial activity and maximum conversion obtained in the first batch were set to 100 . The residual activity was defined as the ratio of the reused enzyme activity relative to the original enzyme activity in the same reaction system.

2.4. Determination of the Enzymatic Kinetic Constants. The kinetic constants of enzymatic sorboylation were investigated at different polydatin concentrations in 2-MeTHF (2$14 \mathrm{mM})$, THF (5-50 mM), acetone (4-16 mM), and $t$-butanol (2-18 mM). The reactions were carried out in $3 \mathrm{~mL}$ solvent containing different polydatin concentration, 9 equiv. of vinyl sorbate, and $100 \mathrm{mg} \mathrm{CALB}$ at $60^{\circ} \mathrm{C}$ and $200 \mathrm{rpm}$. The kinetic constants $\left(K_{m}\right.$ and $\left.V_{\max }\right)$ were calculated from Hanes-Woolf plots.

2.5. Determination of the Enzymatic Apparent Activation Energy $\left(E_{a}\right)$. The apparent activation energy values $\left(E_{a}\right)$ of enzymatic acylation in 2-MeTHF, THF, acetone, and $t$ butanol were investigated. Polydatin $(0.03 \mathrm{mmol})$, CALB $(100 \mathrm{mg})$, and vinyl sorbate $(0.27 \mathrm{mmol})$ were added into the anhydrous solvent $(3 \mathrm{~mL})$ and incubated at different temperatures (in the range of $35-50^{\circ} \mathrm{C}$ ) and $200 \mathrm{rpm} . E_{a}$ value of enzymatic sorboylation was calculated according to the linear regression analysis of the Arrhenius plot.

2.6. NMR and HPLC Analytical Procedure. Qualitative analysis of the reaction mixtures was conducted by HPLC, using a $4.6 \mathrm{~mm} \times 250 \mathrm{~mm}(5 \mu \mathrm{m})$ Eclipse Plus-C18 column (Agilent Technologies Industries Co., Ltd., USA), a UV detector at 
TABLE 1: Effect of solvent on CALB-catalyzed acylation of polydatin with vinyl sorbate ${ }^{\mathrm{a}}$.

\begin{tabular}{lcccccc}
\hline Medium & $\log P$ & Viscosity $^{\mathrm{b}}$ & Solubility $(\mathrm{mM})^{\mathrm{c}}$ & $V_{0}(\mathrm{mM} / \mathrm{h})$ & $\left.C^{\prime \prime}\right)$ & $6^{\prime \prime}$-Regioselectivity $(\%)$ \\
\hline 2-MeTHF & 0.99 & 0.60 & $8.51 \pm 0.42$ & $3.04 \pm 0.15$ & $99.57 \pm 0.03$ & 100 \\
t-Amyl alcohol & 1.24 & 3.70 & $5.87 \pm 0.21$ & $2.40 \pm 0.11$ & $79.31 \pm 0.71$ & 100 \\
t-Butanol & 0.60 & 3.30 & $6.54 \pm 0.26$ & $1.64 \pm 0.05$ & $99.00 \pm 0.02$ & 100 \\
Cyclohexanone & 1.43 & 2.20 & $13.96 \pm 0.39$ & $0.83 \pm 0.06$ & $66.72 \pm 1.01$ & 100 \\
Acetone & -0.23 & 0.32 & $12.63 \pm 0.53$ & $0.62 \pm 0.03$ & $99.00 \pm 0.02$ & 100 \\
THF & 0.49 & 0.55 & $72.17 \pm 2.98$ & $0.35 \pm 0.01$ & $43.22 \pm 1.76$ & 100 \\
Dioxane & -1.10 & 1.30 & $20.72 \pm 1.01$ & $0.21 \pm 0.01$ & $25.16 \pm 1.31$ & 100 \\
\hline
\end{tabular}

${ }^{\mathrm{a}}$ The reactions were carried out at $40^{\circ} \mathrm{C}$ and $200 \mathrm{rpm}$ by adding $0.03 \mathrm{mmol}$ polydatin, $0.15 \mathrm{mmol}$ vinyl sorbate, and $100 \mathrm{mg}$ CALB into $3 \mathrm{~mL}$ anhydrous solvent.

${ }^{\mathrm{b}}$ The viscosity of solvents at $25^{\circ} \mathrm{C}$.

${ }^{c}$ The solubility of polydatin was determined by HPLC analyses of the saturated solutions at $25^{\circ} \mathrm{C}$.

$275 \mathrm{~nm}$, and a solvent mixture system of water and methanol $(40 / 60, \mathrm{v} / \mathrm{v})$ at a flow rate of $1.0 \mathrm{~mL} / \mathrm{min}$. The retention times for polydatin and $6^{\prime \prime}$-ester were 2.59 and $5.27 \mathrm{~min}$, respectively. The acylated derivative was purified by flash column chromatography using ethyl acetate (EA)/petroleum ether $(\mathrm{PE})$ and its chemical structure was determined by ${ }^{13} \mathrm{C}$ NMR $(100 \mathrm{MHz})$ and ${ }^{1} \mathrm{H}$ NMR $(400 \mathrm{MHz})$ (Bruker DRX-400 NMR Spectrometer, Bruker Co., Germany) in DMSO- $d_{6}$.

$6^{\prime \prime}$-O-Sorboyl-polydatin. ${ }^{1} \mathrm{H}$ NMR (DMSO- $d_{6}$ ) $\delta: 9.63$ (br s, $1 \mathrm{H}, \mathrm{OH}$ phenolic), 9.51 (br s, $1 \mathrm{H}, \mathrm{OH}$ phenolic), 7.43 (d, $2 \mathrm{H}$, $\left.J=6.0 \mathrm{~Hz}, \mathrm{H}_{2^{\prime}}+\mathrm{H}_{6^{\prime}}\right), 7.18-7.13\left(\mathrm{~m}, 1 \mathrm{H}, J=18.0 \mathrm{~Hz}, \mathrm{H}_{4^{\prime \prime \prime}}\right)$, $7.05\left(\mathrm{~d}, 1 \mathrm{H}, J=10.8 \mathrm{~Hz}, \mathrm{H}_{\text {vinyl- } 1}\right), 6.91(\mathrm{~d}, 1 \mathrm{H}, J=10.8 \mathrm{~Hz}$, $\left.\mathrm{H}_{3^{\prime \prime \prime}}\right), 6.88\left(\mathrm{t}, 1 \mathrm{H}, J=2.4 \mathrm{~Hz}, \mathrm{H}_{2^{\prime \prime \prime}}\right), 6.87\left(\mathrm{t}, 1 \mathrm{H}, \mathrm{H}_{\text {vinyl-2 }}\right), 6.81$ $\left(\mathrm{d}, 1 \mathrm{H}, J=5.6 \mathrm{~Hz}, \mathrm{H}_{3^{\prime}}\right), 6.70\left(\mathrm{br} \mathrm{s}, 1 \mathrm{H}, \mathrm{H}_{5^{\prime}}\right), 6.63(\mathrm{br} \mathrm{s}, 1 \mathrm{H}$, $\left.\mathrm{H}_{2}\right), 6.36\left(\mathrm{t}, 1 \mathrm{H}, J=1.6 \mathrm{~Hz}, \mathrm{H}_{6}\right), 6.16-6.12\left(\mathrm{~m}, 1 \mathrm{H}, \mathrm{H}_{5^{\prime \prime \prime}}\right)$, $5.80\left(\mathrm{dd}, 1 \mathrm{H}, J=1.2,1.2 \mathrm{~Hz}, \mathrm{H}_{4}\right), 5.42\left(\mathrm{br} \mathrm{s}, 1 \mathrm{H}, \mathrm{OH}_{2^{\prime \prime}}\right)$, $5.36\left(\right.$ br s, $\left.1 \mathrm{H}, \mathrm{OH}_{3^{\prime \prime}}\right), 5.24\left(\right.$ br s, $\left.1 \mathrm{H}, \mathrm{OH}_{4^{\prime \prime}}\right), 4.94(\mathrm{~d}, 1 \mathrm{H}$, $\left.J=5.2 \mathrm{~Hz}, \mathrm{H}_{1^{\prime \prime}}\right), 4.47\left(\mathrm{~d}, 1 \mathrm{H}, J=7.2, \mathrm{H}_{6^{\prime \prime}-1}\right), 4.11(\mathrm{dd}$, $\left.1 \mathrm{H}, J=5.2,5.2 \mathrm{~Hz}, \mathrm{H}_{6^{\prime \prime}-2}\right), 3.74-3.71\left(\mathrm{~m}, 1 \mathrm{H}, \mathrm{H}_{5^{\prime \prime}}\right), 3.39-$ $3.36\left(\mathrm{~m}, 1 \mathrm{H}, \mathrm{H}_{2^{\prime \prime}}\right), 3.32-3.30\left(\mathrm{~m}, 1 \mathrm{H}, \mathrm{H}_{3^{\prime \prime}}\right), 3.25-3.22(\mathrm{~m}, 1 \mathrm{H}$, $\left.\mathrm{H}_{4^{\prime \prime}}\right), 1.71\left(\mathrm{~d}, 3 \mathrm{H}, J=4.4 \mathrm{~Hz}, \mathrm{H}_{6^{\prime \prime \prime}}\right) .{ }^{13} \mathrm{C}$ NMR $\left(\right.$ DMSO- $\left.d_{6}\right)$ $\delta: 166.77\left(\mathrm{C}_{1^{\prime \prime \prime}}\right), 159.05\left(\mathrm{C}_{3}\right), 158.86\left(\mathrm{C}_{5}\right), 157.85\left(\mathrm{C}_{4^{\prime}}\right), 145.64$ $\left(\mathrm{C}_{3^{\prime \prime \prime}}\right), 140.43\left(\mathrm{C}_{4^{\prime \prime \prime}}\right), 139.82\left(\mathrm{C}_{1}\right), 129.86\left(\mathrm{C}_{2^{\prime}}+\mathrm{C}_{6^{\prime}}\right), 128.95$ $\left(\mathrm{C}_{1^{\prime}}\right), 128.40\left(\mathrm{C}_{\text {vinyl-1 }}\right), 125.76\left(\mathrm{C}_{\text {vinyl-2}}\right), 118.75\left(\mathrm{C}_{2^{\prime \prime \prime}}\right), 116.05$ $\left(\mathrm{C}_{3^{\prime}}+\mathrm{C}_{5^{\prime}}\right), 107.62\left(\mathrm{C}_{6}\right), 104.79\left(\mathrm{C}_{2}\right), 103.37\left(\mathrm{C}_{1^{\prime \prime}}\right), 100.55\left(\mathrm{C}_{4}\right)$, $76.89\left(\mathrm{C}_{2^{\prime \prime}}\right), 74.29\left(\mathrm{C}_{5^{\prime \prime}}\right), 73.62\left(\mathrm{C}_{3^{\prime \prime}}\right), 70.59\left(\mathrm{C}_{4^{\prime \prime}}\right), 64.17\left(\mathrm{C}_{6^{\prime \prime}}\right)$, $60.24\left(\mathrm{C}_{5^{\prime \prime \prime}}\right), 18.77\left(\mathrm{C}_{6^{\prime \prime \prime}}\right)$.

2.7. DPPH Scavenging Activity. The antioxidant activity of polydatin and its acylated derivatives was examined according to the previously reported procedure with a few modifications [19]. Briefly, $2 \mathrm{~mL}$ of freshly made DPPH solution was added into ethanol solutions of individual tested compounds to start the reaction at a final concentration of $200 \mu \mathrm{M}$ DPPH. Each compound concentration was fixed at 0.1, 0.2, 0.4, 0.8 , and $1.2 \mathrm{mg} / \mathrm{mL}$, respectively. The absorbance at $517 \mathrm{~nm}$ was measured against a blank of pure ethanol in a light proof reaction vessel at room temperature for $30 \mathrm{~min}$. DPPH scavenging capacity was estimated based on the difference in absorbance and expressed by the remaining radical DPPH percentage. Triplicate reactions were carried out for each antioxidant experiment and the results were based on the average values.

\section{Results and Discussions}

3.1. Selection of Suitable Reaction Media. The search for suitable solvent capable of maintaining enzyme activity, improving enzyme specificity, and accelerating the enzymatic reaction process has always been a central problem for biochemists $[20,21]$. So far, no empirical regularities could be followed to guide the rational choice of the solvent system in nonaqueous enzymology. The solvent physicochemical properties such as the $\log P$, dielectric constant, viscosity, dissolving capacity, and molecular size unpredictably affect the behavior of the enzyme. Hence, eight organic solvents with different $\log P$ values $(-1.10-1.43)$ were selected to further evaluate their effects on the CALB-mediated sorboylation of polydatin.

As shown in Table 1, the initial reaction rate and conversion of the biocatalytic sorboylation varied greatly with the use of different solvents. For the regioselectivity, it is interesting to note that the solvents investigated gave exclusively acylation at the $6 "$-hydroxyl group. However, there was not an inevitable correlation between the enzyme activity and solvent properties including the $\log P$, viscosity, and substrate solubility in this acylation. In those solvents such as THF, dioxane, cyclohexanone, and $t$-amyl alcohol, CALB displayed poor to good activities with $25.16-79.31 \%$ maximal conversions. By contrast, acetone and $t$-butanol seemed to be selectable media and gave $99.00 \%$ substrate conversions, but the initial rates were far from satisfactory $(0.62-1.64 \mathrm{mM} / \mathrm{h})$. However, when the reaction was carried out in ecofriendly 2-MeTHF, CALB showed highest reaction rate $(3.04 \mathrm{mM} / \mathrm{h})$ and excellent conversion $(99.57 \%)$, indicating that the biomass-derived 2-MeTHF exhibited prominent biocompatibility with the lipase compared to the other conventional organic media. Furthermore, compared with the acetone and $t$-butanol, 2-MeTHF may be more beneficial to maintain enzyme activity owing to its more hydrophobic character [22]. 


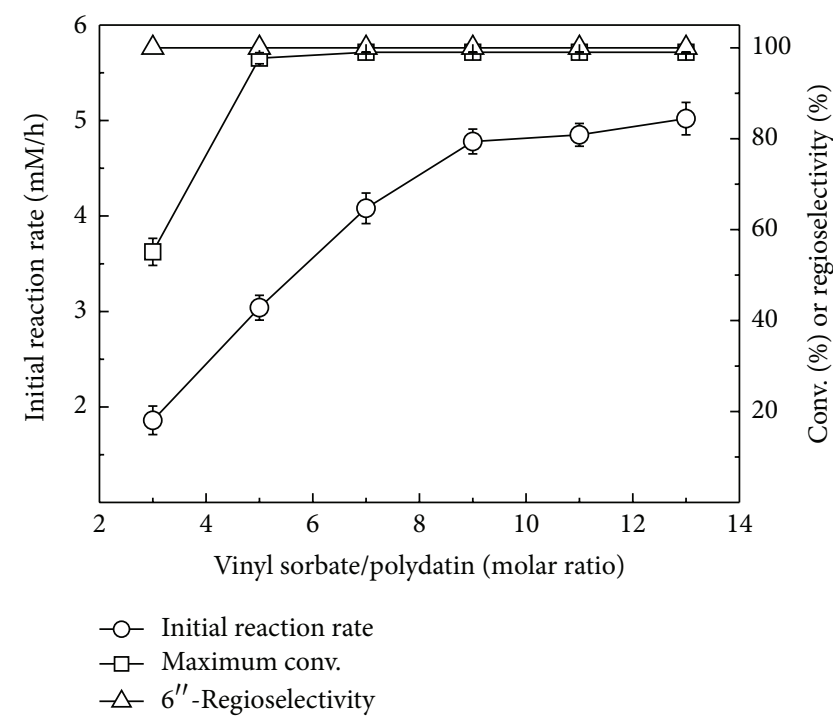

(a)

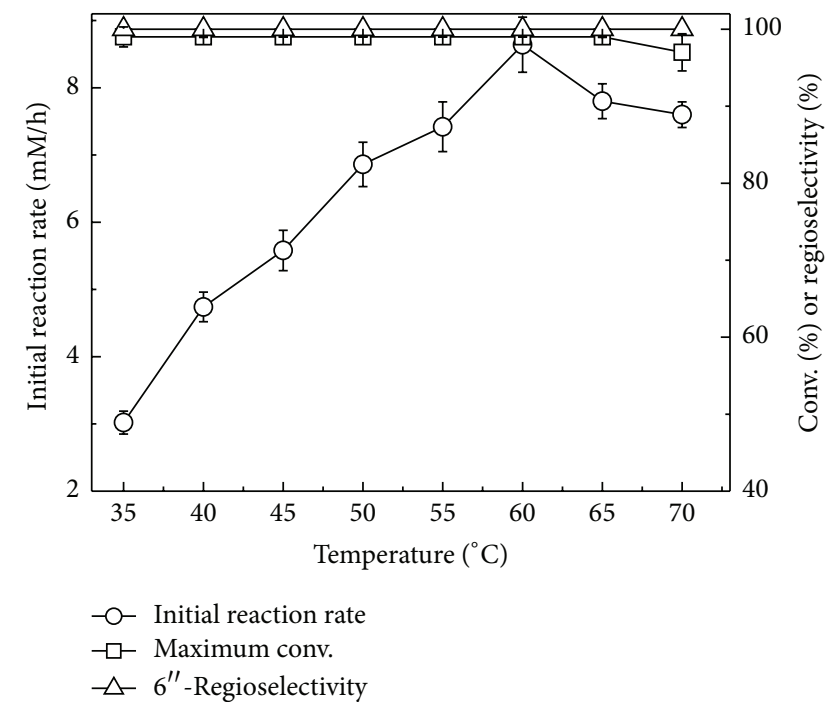

(b)

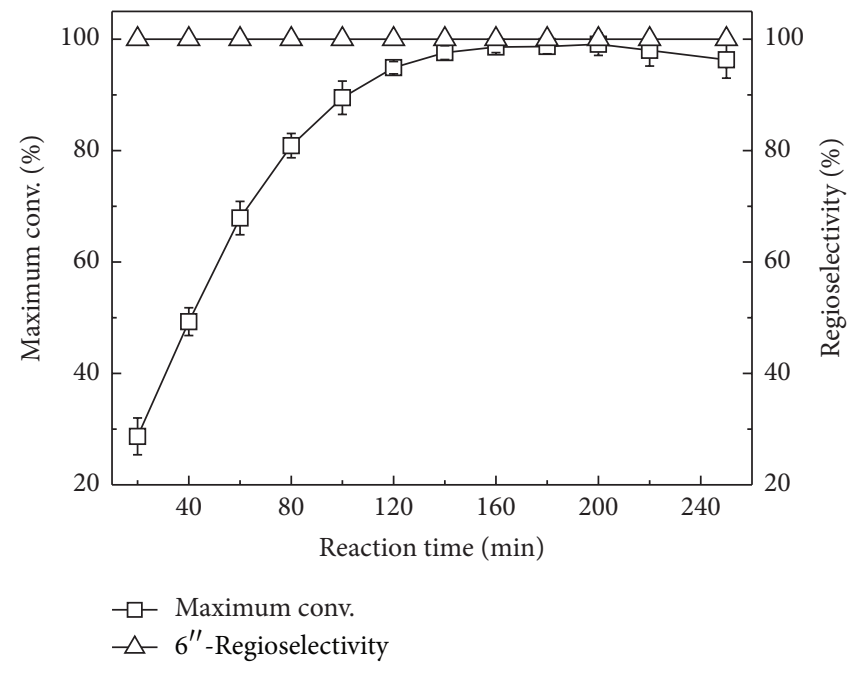

(c)

Figure 1: Effect of the molar ratio of vinyl sorbate to polydatin (a), temperature (b), and reaction time (c) on CALB-catalyzed acylation of polydatin. Reaction conditions: (a) $0.03 \mathrm{mmol}$ polydatin, $100 \mathrm{mg}$ CALB, $3 \mathrm{~mL}$ anhydrous 2-MeTHF, $200 \mathrm{rpm}$, various amounts of vinyl sorbate, $40^{\circ} \mathrm{C}$; (b) $0.03 \mathrm{mmol}$ polydatin, $100 \mathrm{mg}$ CALB, $3 \mathrm{~mL}$ anhydrous 2-MeTHF, $200 \mathrm{rpm}, 0.27 \mathrm{mmol}$ vinyl sorbate, different temperatures from 35 to $70^{\circ} \mathrm{C}$; (c) $0.03 \mathrm{mmol}$ polydatin, $100 \mathrm{mg}$ CALB, $3 \mathrm{~mL}$ anhydrous 2-MeTHF, $200 \mathrm{rpm}$, $60^{\circ} \mathrm{C}$, reaction time from 20 to $250 \mathrm{~min}$.

3.2. Effect of the Substrate Molar Ratio, Temperature, and Reaction Time. The influence of some crucial factors, such as the substrate molar ratio, temperature, and reaction time, was also investigated in detail. As can be seen in Figure 1(a), the optimal molar ratio of vinyl sorbate to polydatin was shown to be 9 , suggesting that an excessive amount of vinyl sorbate is required due to the reversibility of the reaction. Temperature has a considerable effect on the conformational unfolding of the protein and the reaction equilibrium as well. Figure 1(b) illustrates that there was 1.9 times increase in the initial rate when the temperature was raised from 35 to $60^{\circ} \mathrm{C}$, beyond which further increasing temperature brought a slight drop in the initial reaction rate and maximum conversion. Lipase deactivation caused by high temperature may be one of the reasonable explanations for this phenomenon.

Gardossi et al. recently demonstrated that it is very necessary to monitor the procedure parameters (such as the reaction rate, selectivity, and yield) at a single timepoint [23]. So, the time course of producing 6 " $-O$-sorboyl-polydatin was followed under the optimal conditions for better understanding the enzymatic process. It was found in Figure 1(c) that the rate of substrate conversion underwent a steep increment within $80 \mathrm{~min}$ and then a smooth rise with prolonging the incubation time up to $160 \mathrm{~min}$. This phenomenon may occur because the acetaldehyde and sorbic acid from the vinyl sorbate partially inactivated the biocatalyst [24, 25]. After 


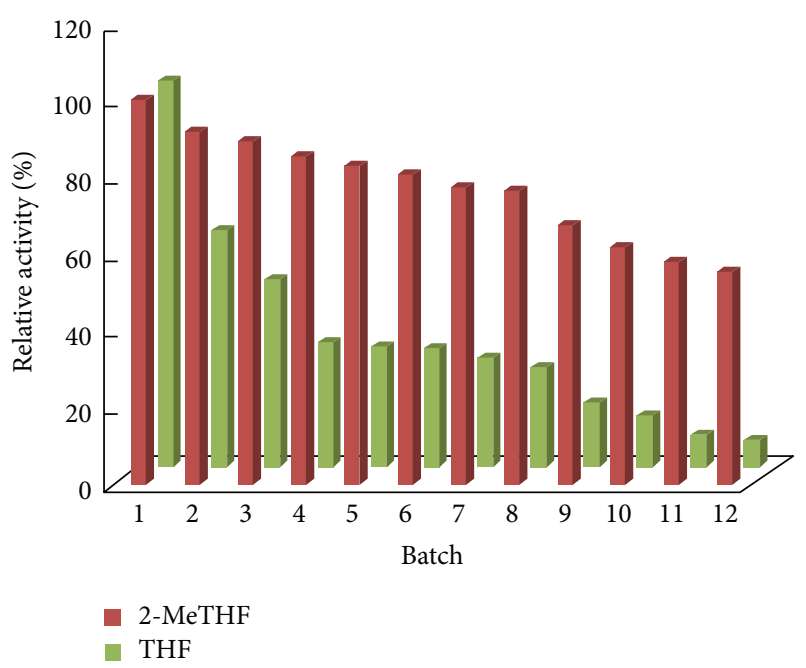

(a)

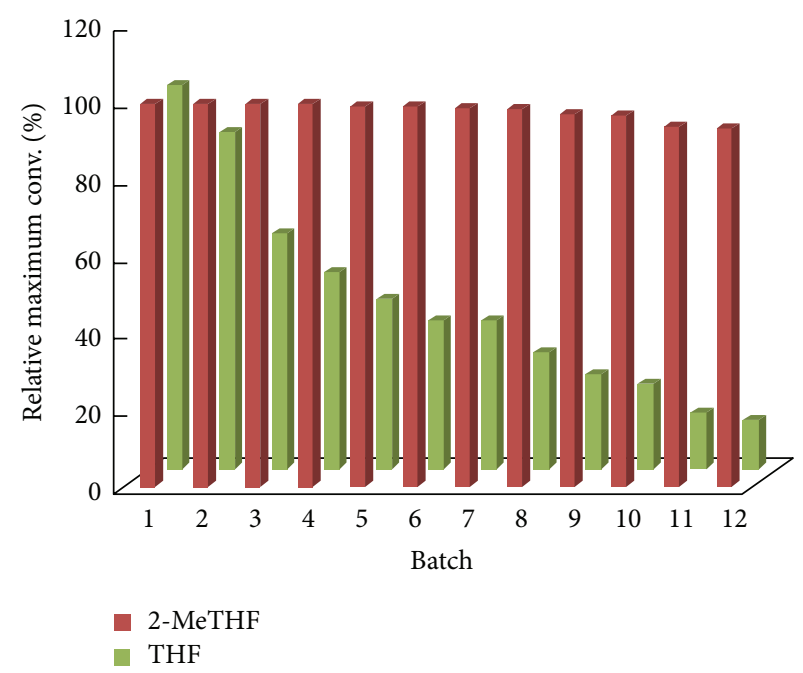

(b)

FIGURE 2: Operational stability of CALB in 2-MeTHF and THF. The reactions were carried out at $60^{\circ} \mathrm{C}$ and $200 \mathrm{rpm}$ by adding $0.03 \mathrm{mmol}$ polydatin, $0.27 \mathrm{mmol}$ vinyl sorbate, and $100 \mathrm{mg}$ CALB into $3 \mathrm{~mL}$ anhydrous 2-MeTHF.

reaching a maximum (200 $\mathrm{min})$, the substrate conversion gradually dropped with extended reaction time, which is in accordance with our previous studies and means that the acylated product was enzymatically hydrolyzed during subsequent reaction process [26].

\subsection{Operational Stability of the CALB. The successful incor-} poration of biocatalysts into fine chemicals production requires not only high catalytic activities but also excellent operational stabilities. The results for repeated uses of the enzyme in 2-MeTHF and THF are presented in Figure 2 and the differences are evident. The catalytic activity of CALB decreased only slightly during the first two batches in 2MeTHF, with around $89.27 \%$ of its original activity being retained after the second batch, whereas only about $48.73 \%$ was obtained in THF. In particular, after eight successive cycles of reuse, CALB still displayed 2.9 times the residual activity $(76.34 \%$ versus $26.00 \%)$ in 2 -MeTHF compared to in THF. Similarly, for the maximal conversion of the operational stability, the catalyst remained $93.24 \%$ and $13.21 \%$, respectively, of their initial maximal conversions in ecofriendly 2-MeTHF and traditional THF after being used repeatedly for 12 batches, showing that the biomass-derived 2-MeTHF exhibited a great potential as the reaction medium for the enzyme-catalyzed acylation.

3.4. Kinetic Studies. For better understanding the superiority of 2-MeTHF, measurement of kinetic constants of enzymatic sorboylation by using linear Hanes-Woolf plots was successfully explored. As illustrated in Table 2, the apparent Michaelis constant $K_{m}$ value of the enzyme in 2-MeTHF $(27.9 \mathrm{mM})$ is much lower than those attained in $t$-butanol, acetone, and THF (100.3, 103.2, and 107.2 mM, resp.). Simultaneously, the catalytic efficiency of CALB varied greatly, depending on the nature of media. For instance, CALB
TABLE 2: Effect of polydatin concentration on enzymatic acylation in various solvents ${ }^{\mathrm{a}}$.

\begin{tabular}{lccc}
\hline Medium & $V_{\max }(\mathrm{mM} / \mathrm{h})$ & $K_{m}(\mathrm{mM})$ & $V_{\max } / K_{m}\left(\mathrm{~h}^{-1}\right)$ \\
\hline 2-MeTHF & 31.2 & 27.9 & 1.12 \\
tert-Butanol & 30.8 & 100.3 & 0.41 \\
Acetone & 24.7 & 103.2 & 0.24 \\
THF & 23.3 & 107.2 & 0.22 \\
\hline
\end{tabular}

${ }^{\mathrm{a}}$ The reactions were carried out at $60^{\circ} \mathrm{C}$ and $200 \mathrm{rpm}$ by adding various amounts of polydatin, vinyl sorbate (9 equiv.), and $100 \mathrm{mg}$ CALB into $3 \mathrm{~mL}$ anhydrous solvent.

afforded the highest $V_{\max } / K_{m}$ value of $1.12 \mathrm{~h}^{-1}$ in 2-MeTHF system, which is 3.7- to 5.5-fold higher than that in other solvents studied. These promising observations indicated that the enzyme exerted an extremely higher affinity for the substrate and catalytic efficiency in this novel 2-MeTHF as compared to normal organic solvents.

The apparent activation energy $\left(E_{a}\right)$ for the reaction is also determined by plotting the data in an Arrhenius plot (Figure 3). The obtained $E_{a}$ value of $43.3 \mathrm{KJ} / \mathrm{mol}$ in 2 MeTHF is lower than that of the sorboylation in other media used (50.7-54.9 KJ/mol) suggesting that the application of 2MeTHF has proved to be more beneficial for overcoming the reaction energy barrier and rendering the process of enzymatic biotransformation.

3.5. Radical DPPH Scavenging Activity. Based on the optimization of the enzymatic sorboylation, $6^{\prime \prime}-O$-crotonyl- and $6^{\prime \prime}$-O-undecenoyl-polydatin were also successfully synthesized for better evaluation of the free radical scavenging activity of the unsaturated polydatin ester derivatives. As depicted in Figure 4, all of the tested compounds displayed the obvious dosage-effect relationship on DPPH radical quenching capacity and the higher concentrations were more 


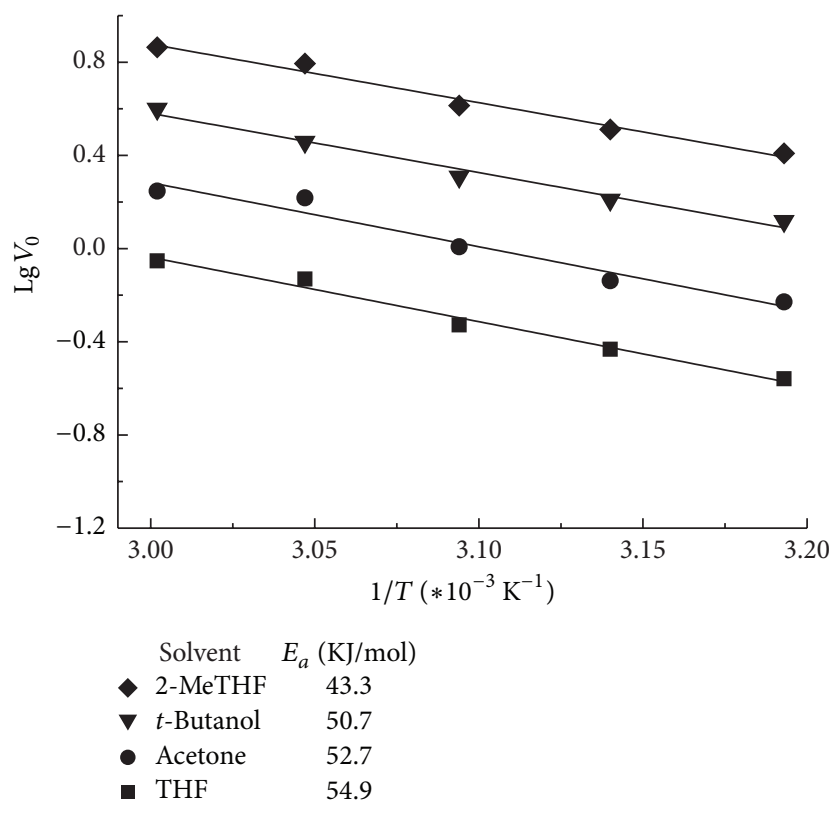

FIGURE 3: Arrhenius plots of CALB-catalyzed acylation of polydatin in various media. The reactions were carried out at different temperatures and $200 \mathrm{rpm}$ by adding $0.03 \mathrm{mmol}$ polydatin, $0.27 \mathrm{mmol}$ vinyl sorbate, and $100 \mathrm{mg}$ CALB into $3 \mathrm{~mL}$ anhydrous 2-MeTHF.

effective in quenching free radicals. When the concentration was fixed at $1.2 \mathrm{mg} / \mathrm{mL}$, for instance, all the unsaturated acylated products exhibited superior antioxidant activity (94.5-96.4\%). However, the scavenging activities of three acylates were always lower than those of the corresponding concentrations of the parent agent. This is in agreement with the previous findings on the acylated flavonoids [27, 28]. For the effect of the aliphatic acid chain length, the unexpected gradual decreases of the free radical scavenging activities were obtained with the increment in the unsaturated aliphatic chain length from $\mathrm{C} 4$ to $\mathrm{C} 11$. One of the most possible reasons might be that the increased steric hindrance derived from the acyl residues in derivatives prevents the substrate molecule from smoothly entering radical active sites and thus reducing the DPPH scavenging activity.

\section{Conclusions}

In this paper, a practical enzymatic approach for acylating polydatin with vinyl sorbate in biomass-derived 2-MeTHF is described for the first time. CALB lipase was used successfully to acylate polydatin at the $6^{\prime \prime}$-position. Detailed investigations have revealed that the enzyme in 2-MeTHF gave the lowest $K_{m}$ and $E_{a}$ values, highest $V_{\max }$, and excellent operational stability, which suggested that this ecofriendly solvent could render the enzyme much higher affinity for the substrate and catalytic efficiency. For the antioxidant activity, introducing the acyl group into the polydatin would result in the slight reduction of its DPPH radical scavenging capacity. In addition, more detailed physicochemical investigations on the $\mathrm{pH}$ stability, 1-octanol-water partition coefficient $(\log P)$,

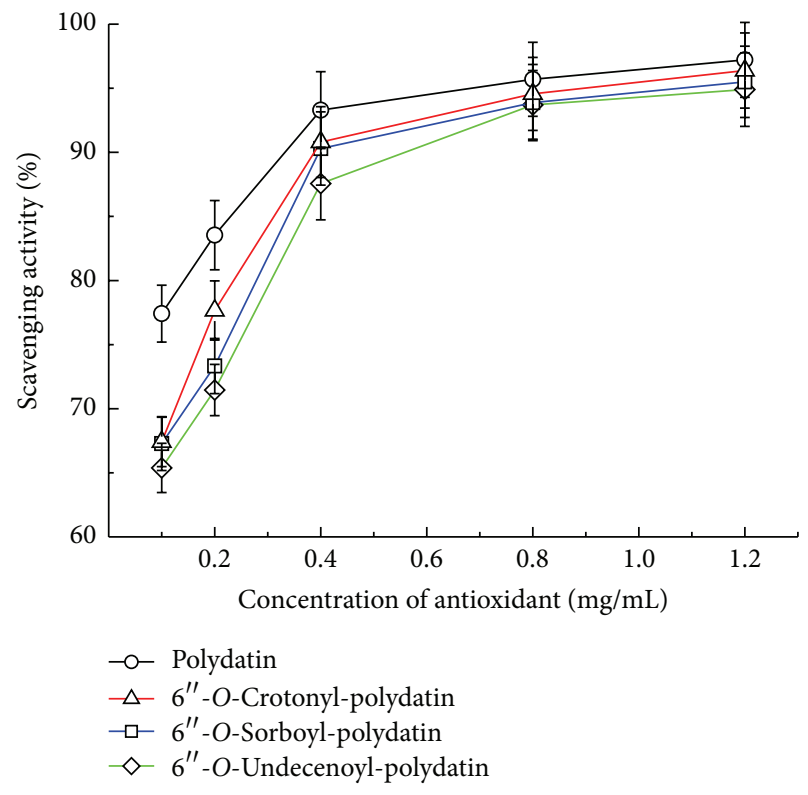

FIGURE 4: Comparison of radical DPPH scavenging capacity.

apoptosis-inducing capability, and so forth of the acylated products are currently in process and will be reported in due course.

\section{Competing Interests}

The authors declare that there are no competing interests regarding the publication of this paper.

\section{Authors' Contributions}

Zhaoyu Wang and Yanhong Bi have made equal contributions.

\section{Acknowledgments}

This work was supported by the National Natural Science Foundation of China (21676114, 31501421), Qing Lan Project of Jiangsu Province, Key Research Program of Industry and Information Technology of Huaian (HAG2015031), Natural Science Research Project of Higher Education of Jiangsu Province (16KJB530001), Natural Science Foundation of Jiangsu Province (BK2012243), and Foundation of Huaiyin Institute of Technology (HGB1401).

\section{References}

[1] J. Hao, C. Chen, K. Huang et al., "Polydatin improves glucose and lipid metabolism in experimental diabetes through activating the Akt signaling pathway," European Journal of Pharmacology, vol. 745, pp. 152-165, 2014.

[2] W. Peng, R. Qin, X. Li, and H. Zhou, "Botany, phytochemistry, pharmacology, and potential application of Polygonum cuspidatum Sieb.et Zucc.: a review," Journal of Ethnopharmacology, vol. 148, no. 3, pp. 729-745, 2013. 
[3] H. Mu, R. Holm, and A. Müllertz, "Lipid-based formulations for oral administration of poorly water-soluble drugs," International Journal of Pharmaceutics, vol. 453, no. 1, pp. 215-224, 2013.

[4] C. J. H. Porter, N. L. Trevaskis, and W. N. Charman, "Lipids and lipid-based formulations: optimizing the oral delivery of lipophilic drugs," Nature Reviews Drug Discovery, vol. 6, no. 3, pp. 231-248, 2007.

[5] L. Lin, B. Ni, H. Lin et al., "Traditional usages, botany, phytochemistry, pharmacology and toxicology of Polygonum multiflorum Thunb.: a review," Journal of Ethnopharmacology, vol. 159, pp. 158-183, 2015.

[6] G. Céliz and M. Daz, "Biocatalytic preparation of alkyl esters of citrus flavanone glucoside prunin in organic media," Process Biochemistry, vol. 46, no. 1, pp. 94-100, 2011.

[7] M. H. Katsoura, A. C. Polydera, L. Tsironis, A. D. Tselepis, and H. Stamatis, "Use of ionic liquids as media for the biocatalytic preparation of flavonoid derivatives with antioxidant potency," Journal of Biotechnology, vol. 123, no. 4, pp. 491-503, 2006.

[8] A. Díaz-Rodríguez, S. Fernández, I. Lavandera, M. Ferrero, and V. Gotor, "Novel and efficient regioselective enzymatic approach to $3^{\prime}$-, $5^{\prime}$ - and $3^{\prime}, 5^{\prime}$-di-O-crotonyl $2^{\prime}$-deoxynucleoside derivatives," Tetrahedron Letters, vol. 46, no. 35, pp. 5835-5838, 2005.

[9] C. H. Kim, M. Kang, H. J. Kim, A. Chatterjee, and P. G. Schultz, "Site-Specific incorporation of $\varepsilon$-N-crotonyllysine into histones," Angewandte Chemie International Edition, vol. 51, no. 29, pp. 7246-7249, 2012.

[10] A. M. Gumel, M. S. M. Annuar, T. Heidelberg, and Y. Chisti, "Lipase mediated synthesis of sugar fatty acid esters," Process Biochemistry, vol. 46, no. 11, pp. 2079-2090, 2011.

[11] L. E. Iglesias, E. S. Lewkowicz, R. Medici, P. Bianchi, and A. M. Iribarren, "Biocatalytic approaches applied to the synthesis of nucleoside prodrugs," Biotechnology Advances, vol. 33, no. 5, pp. 412-434, 2015.

[12] Z.-Y. Wang, Y.-H. Bi, R.-L. Yang et al., "The halo-substituent effect on Pseudomonas cepacia lipase-mediated regioselective acylation of nucleosides: a comparative investigation," Journal of Biotechnology, vol. 212, pp. 153-158, 2015.

[13] Z.-Y. Wang, Y.-H. Bi, X.-Q. Li, and M.-H. Zong, "Influence of substituent groups in regioselective acylation of nucleosides by Novozym 435 lipase," Process Biochemistry, vol. 48, no. 8, pp. 1208-1211, 2013.

[14] Y. Gu and F. Jérôme, "Bio-based solvents: an emerging generation of fluids for the design of eco-efficient processes in catalysis and organic chemistry," Chemical Society Reviews, vol. 42, no. 24, pp. 9550-9570, 2013.

[15] V. Pace, P. Hoyos, L. Castoldi, D. M. P. Domínguez, and A. R. Alcántara, "2-Methyltetrahydrofuran (2-MeTHF): a biomassderived solvent with broad application in organic chemistry," ChemSusChem, vol. 5, no. 8, pp. 1369-1379, 2012.

[16] Y. Simeó, J. V. Sinisterra, and A. R. Alcántara, "Regioselective enzymatic acylation of pharmacologically interesting nucleosides in 2-methyltetrahydrofuran, a greener substitute for THF," Green Chemistry, vol. 11, no. 6, pp. 855-862, 2009.

[17] Z. Cabrera, G. Fernandez-Lorente, R. Fernandez-Lafuente, J. M. Palomo, and J. M. Guisan, "Novozym 435 displays very different selectivity compared to lipase from Candida antarctica B adsorbed on other hydrophobic supports," Journal of Molecular Catalysis B: Enzymatic, vol. 57, no. 1-4, pp. 171-176, 2009.

[18] R. T. Otto, H. Scheib, U. T. Bornscheuer, J. Pleiss, C. Syldatk, and R. D. Schmid, "Substrate specificity of lipase B from Candida antarctica in the synthesis of arylaliphatic glycolipids," Journal of Molecular Catalysis B: Enzymatic, vol. 8, no. 4-6, pp. 201-211, 2000 .

[19] S. Thusoo, S. Gupta, R. Sudan et al., "Antioxidant activity of essential oil and extracts of Valeriana jatamansiroots," BioMed Research International, vol. 2014, Article ID 614187, 4 pages, 2014.

[20] G. Paggiola, A. J. Hunt, C. R. McElroy, J. Sherwood, and J. H. Clark, "Biocatalysis in bio-derived solvents: an improved approach for medium optimisation," Green Chemistry, vol. 16, no. 4, pp. 2107-2110, 2014.

[21] N. Doukyu and H. Ogino, "Organic solvent-tolerant enzymes," Biochemical Engineering Journal, vol. 48, no. 3, pp. 270-282, 2010.

[22] Z.-G. Chen, D.-N. Zhang, L. Cao, and Y.-B. Han, "Highly efficient and regioselective acylation of pharmacologically interesting cordycepin catalyzed by lipase in the eco-friendly solvent 2-methyltetrahydrofuran," Bioresource Technology, vol. 133, pp. 82-86, 2013.

[23] L. Gardossi, P. B. Poulsen, A. Ballesteros et al., "Guidelines for reporting of biocatalytic reactions," Trends in Biotechnology, vol. 28, no. 4, pp. 171-180, 2010.

[24] Z.-Y. Wang, N. Li, and M.-H. Zong, "A simple procedure for the synthesis of potential 6-azauridine prodrugs by Thermomyces lanuginosus lipase," Journal of Molecular Catalysis B: Enzymatic, vol. 59, no. 1-3, pp. 212-219, 2009.

[25] H. K. Weber, H. Weber, and R. J. Kazlauskas, “'Watching' lipasecatalyzed acylations using ${ }^{1} \mathrm{H}$ NMR: competing hydrolysis of vinyl acetate in dry organic solvents," Tetrahedron: Asymmetry, vol. 10, no. 14, pp. 2635-2638, 1999.

[26] Z.-Y. Wang and M.-H. Zong, "Recognition of acyl donors by lipase CAL-B in the acylation of 6-azauridine," Biotechnology Progress, vol. 25, no. 3, pp. 784-791, 2009.

[27] X. Ma, R. Yan, S. Yu, Y. Lu, Z. Li, and H. Lu, "Enzymatic acylation of isoorientin and isovitexin from bamboo-leaf extracts with fatty acids and antiradical activity of the acylated derivatives," Journal of Agricultural and Food Chemistry, vol. 60, no. 43, pp. 10844-10849, 2012.

[28] J. H. Salem, I. Chevalot, C. Harscoat-Schiavo, C. Paris, M. Fick, and C. Humeau, "Biological activities of flavonoids from Nitraria retusa (Forssk.) Asch. and their acylated derivatives," Food Chemistry, vol. 124, no. 2, pp. 486-494, 2011. 

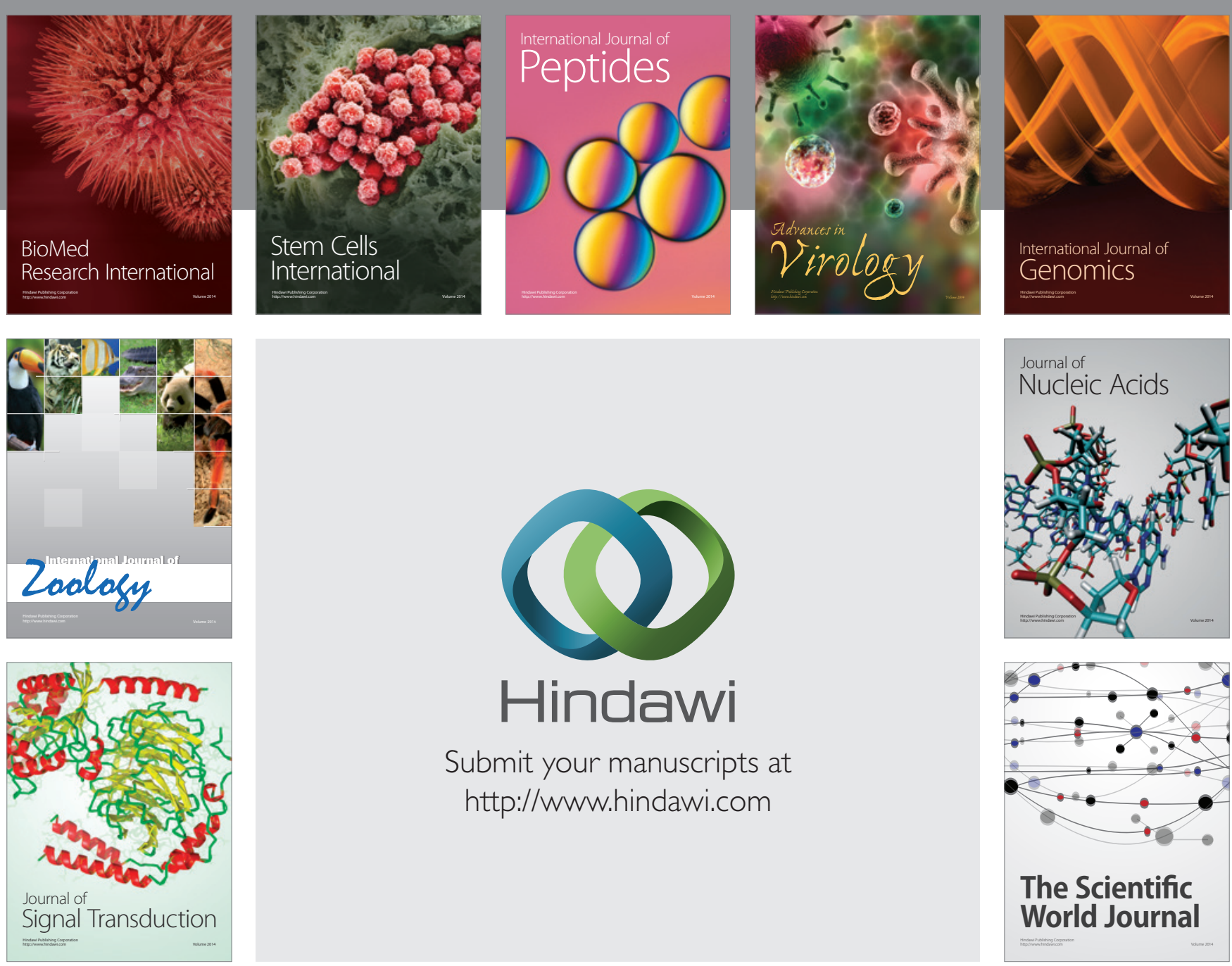

Submit your manuscripts at

http://www.hindawi.com
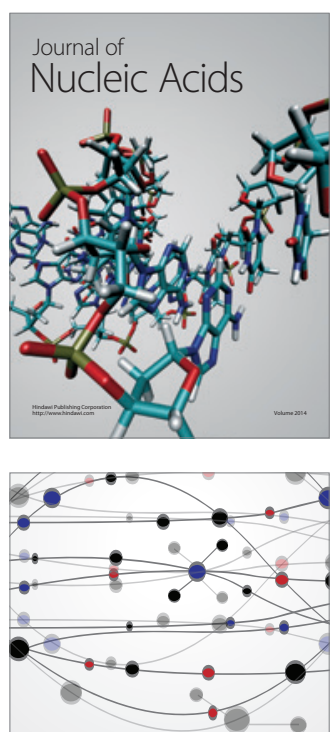

The Scientific World Journal
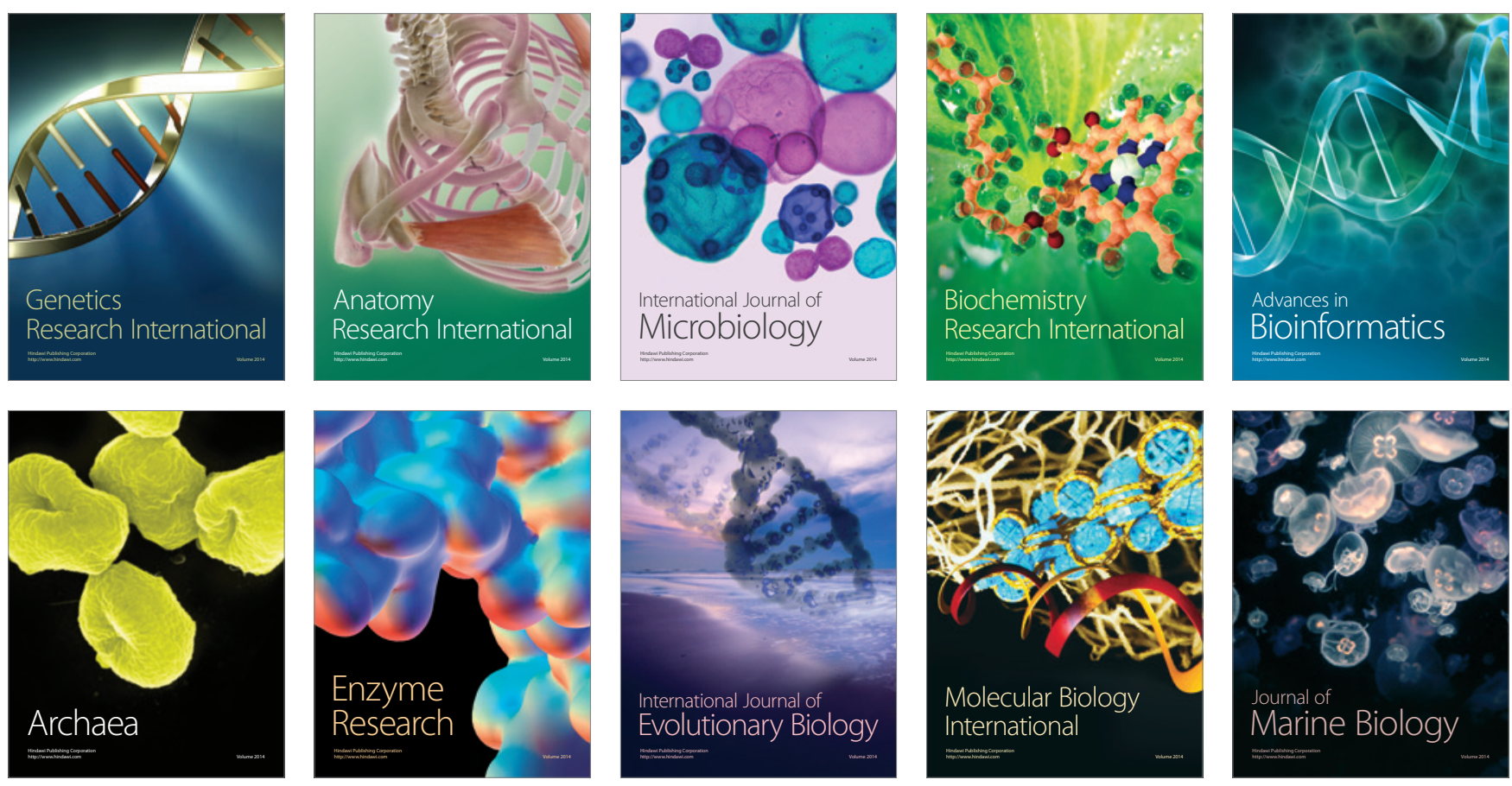